\title{
Report
}

\section{Bishiklik Petroglyphs in Neyshabur County, Northeastern Iran}

\author{
Mohammad Hossein Rezaei ${ }^{1, ~ *}$, Saber Soleymani ${ }^{1}$, Kourosh Ahmadi ${ }^{2}$ \\ ${ }^{1}$ Faculty of Humanities, Department of Archaeology in University of Neyshabur, Neyshabur, Iran \\ ${ }^{2}$ Faculty of Humanities, Archaeology, Islamic Azad University of Kazerun, Kazerun, Iran
}

\section{Email address:}

mohammad.1561@yahoo.com (M. H. Rezaei)

${ }^{*}$ Corresponding author

\section{To cite this article:}

Mohammad Hossein Rezaei, Saber Soleymani, Kourosh Ahmadi. Bishiklik Petroglyphs in Neyshabur County, Northeastern Iran. International Journal of Archaeology. Vol. 4, No. 2, 2016, pp. 11-16. doi: 10.11648/j.ija.20160402.11

Received: April 5, 2016; Accepted: April 14, 2016; Published: April 27, 2016

\begin{abstract}
Neyshabur County is located in the North East of Iran. This county borders to Binaloud mountain range and Qochan County from the north, to Esferayen and Sabzevar counties from the west, to Kashmar and Torbate heydarieh counties from south and to Mashhad County from east. Neyshabur County has witnessed human settlements in different periods because of fertile plains and abundant hydrological resources. Bishiklik petroglyphs are located within $30 \mathrm{~km}$ of Neyshabur -Kashmar road (6 km southeast of Kalateh Hassan Abad village), which has direct access via a dirt road passing through the village. A few motifs have been engraved on the smooth surface of a large boulder by percussion and carving techniques. The depth and color of the motifs even those in the same scene is different, so that the depth of some of the motifs has been eroded over time through the effect of natural factors and is not visible since it has become level with the boulder. Stone engraving motifs include stylized animal motifs such as canines as well as a human on horseback motif, mountain goat with large exaggerated backward horns, which forms the majority of the motifs in petroglyphs of Bishiklik. Unfortunately, despite the large number of Rock engravings (rock art) throughout Iran, this rock art has been rarely subject to research and precise analysis. This challenges becomes complicated in North East of Iran (Khorasan) as the poorest region in the field of archaeological research. These issues as well as the poor status of Bishiklik petroglyphs made us evaluate and introduce this valuable relic.
\end{abstract}

Keywords: Petroglyphs, Bishiklik, Animal Motifs, Neyshabur

\section{Introduction}

The rock art or petroglyphs on stone and boulder is an ancient method of expression of beliefs and thoughts for man. The rock art dates back to over 30 thousand years ago; however, the study of prehistoric motifs in Iran is relatively contemporary in comparison with the other archaeological studies. The rock art has managed to display the first known sights of artistic sensitivity and aesthetics of distant ancestors of humans in many parts of the world with a significant representation (Rafifar, 2002: 46).

Despite a lot of similarities in terms of motif themes, the petroglyphs frequently involve hunting scenes, battles and single image of a mountain goat. In terms of implementation technique, the engravings have been carved and threshed, and have been created by tapping on the rock face using a rigid object in a low depth. Stone engraving themes are affected by geographical, cultural and environmental conditions of each region. Nowadays, Rock engravings involve a large spectrum of periods from Paleolithic to the contemporary. The main problem of these engravings is lack of absolute chronology in them, and their history and specific period can only be specified as comparative chronology (Rezayi \& Judi, 2010:3).

The study of petroglyphs in Iran was undertaken by Italian researchers. In 1958, when a group of Italian geologists were busy exploring and extracting the minerals in the Baluchistan region, they discovered a number of rock paintings in Gazu district (Dessau 1960). This discovery can be regarded as the first research on petroglyphs in Iran (Mohammadi Qasrian, A. 
2007:19). The preliminary report of McBourny after examining rock engravings by Douche and Mirmalas in 1969 can be considered as the first preliminary review on petroglyphs in Iran (Bourny, 1969:14-16). The most important and profuse motifs of Iranian Nowadays engravings is Timereh, the collection of motifs of which has been published in the form of a comprehensive book in 1998 (Farhadi, 1998: 65-66). Although these works of art have been identified in many parts of Iran, there are still many uncertainties about their function and meaning, which prevents accurate determination of their exact cultural-historical position.

The heritage of Iranian civilization for the world arises from their rich peace-loving culture. Nowadays petroglyphs (art rock) form a significant portion of this valuable heritage, which unfortunately have been seldom subject to precise research despite their multitude throughout Iran, which is a challenge in the North East of Iran (Khorasan) as the poorest region in the field of archaeological research. These issues on the one hand and the poor status of the petroglyphs of Bishiklik in Neyshabur on the other made us evaluate and introduce this valuable work. Although this article may not be capable of full expression of the capacities and characteristics of this work, we do our best to register and record the endangered data of this valuable petroglyphs.

\subsection{Geographical Situation and Unevenness in the County}

Neyshabur County is located in the North East of Iran. The surface area of this county is 9308 square kilometers, and it is limited to north by Binaloud mountain range and Qochan County, to west by Esfarayen and Sabzevar counties, to south by Kashmar and Torbate heydarieh counties and to east by Mashhad County (Figure 1). Neyshabur Plain is situated on the slopes of Binaloud mountains, which is the highest mountains of Khorasan (Taheri, 2005:7; Velayati 1988: 96).Foothill plain of Neyshabur involves foothills and southern lowlands in terms of geology, which includes suitable hydrological factors along with other items, providing for human settlements in different historical periods (Basafa, 2011: 58). Neyshabur Plain has a moderate sloping towards southwest. The importance of this plain in the past centuries and now is due to presence of four rivers that originate from Binaloud and all drain to Kalshoor River (Taheri, 2005: 7). Ecological potentials such as matter, energy, space, time and diversity (Watts 2007: 60) have made this plain as one of the most fertile areas of Khorasan. According to geologic conditions and considering the natural and cultural processes, Neyshabour Plain is not directly affected by deserts (Riyazi 1992: 21).Thus, this plain has natural and biological resources, is not faced with space limitation and has had the necessary factors for development of human societies in long term cultural processes (Garazhyan 2008: 3).

From the total surface area of Neyshabur County, about 5500 square kilometers is formed by plain and the rest by highlands. The heights of northern have formed a suitable factor to provide a good substrate for human settlements in chronological processes, and have provided proper climatic conditions and water resources. This mountain range is called Binaloud and has northwest-southeast slope and is the continuation of Alborz mountain range in Khorasan. The highest point of the mountain is Binaloud summit and is 3200 to 3400 meters above sea level, causing it to be known as Khorasan roof. The climate of Neyshabur is different with respect to the height of its southern and northern regions. The climate is temperate and cold in the northern and southern mountains, is temperate in the central plains, and is considered a dry region in terms of rainfall (Taheri, 2005: 8). It seems necessary to address some of the climatic characteristics of Reysi region where the Rock engravings are located, as this engraving is directly influenced by these parameters. The winds as one of the important elements of this climate have affected the geology of the region, so that it is situated in a corridor of monsoon. On the other hand, this region is an example of the desert ecosystems in which the torrential downpour causes erosion and leaching of the soil. The percentage of minerals is noteworthy in the soil in this region, which prevents the formation of rich vegetation in this region.

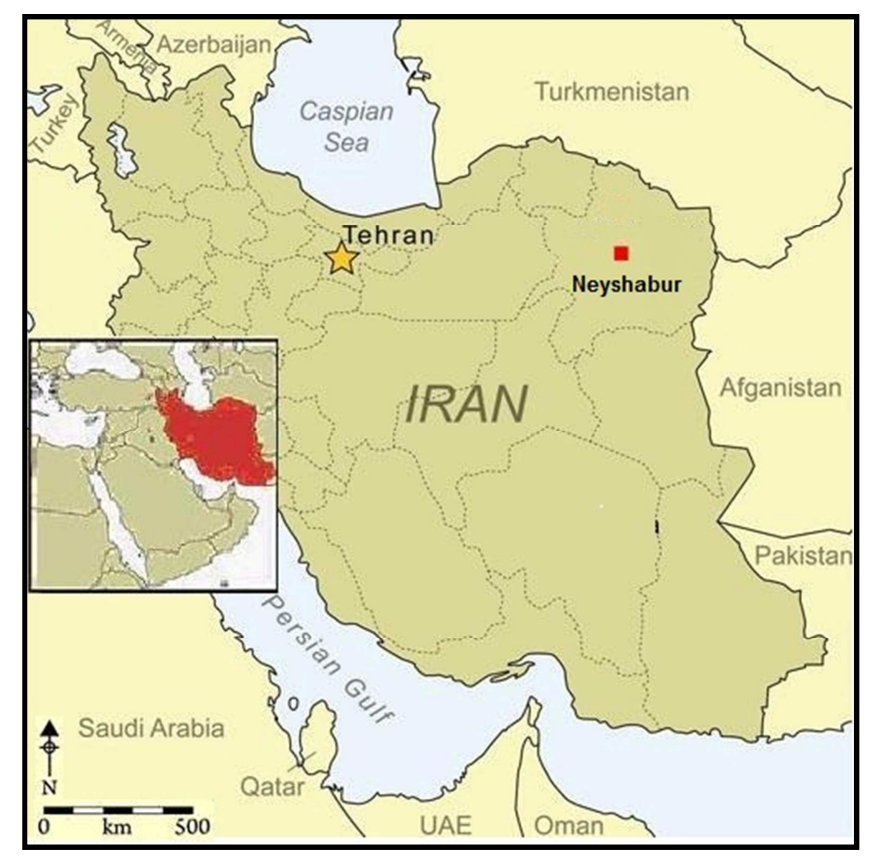

Figure 1. Location of Neyshabur.

\subsection{The Position of the Petroglyphs}

Bishiklik Rock engravings with N 355330 E 583920 coordinates are located within $30 \mathrm{Km}$ of Neyshabur-Kashmar road (6 km southeast of the village of Kalateh Hassan Abad) with access via a dirt road passing from the village (Figure 2). Mr. Ahmad Reza Salem and Mr. Momen Nejad for the first time presented a brief report of this Rock engraving in web site of the Iranian petroglyphs. Location of the Rock engravings is known as Kamar Beshkeli for the locals, and the petroglyphs of Bishiklik is known as talisman stone for them. A $3 \mathrm{~m}$ deep pit has been dug under this boulder probably to 
find treasures. In Kamar Bishikli region, boulders separated from the mountain are found in the foothill, and different animal motifs (usually mountain goat) have been engraved on them (Figure 3). The largest boulder on which the engravings are found is nearly $4.20 \mathrm{~m}$ high and $3.20 \mathrm{~m}$ wide. The motifs have been engraved on the smooth surface of small and large boulders, which shows cracks and lamination due to the nature of stones and erosion over time.

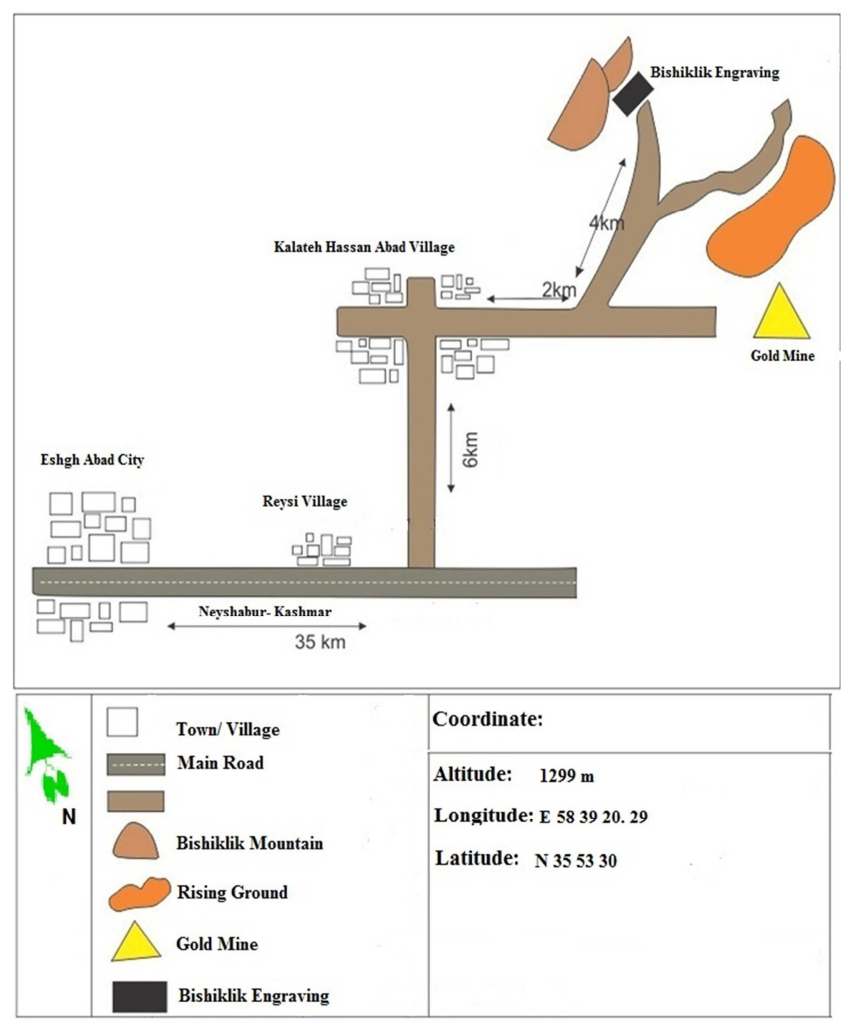

Figure 2. Sketch of Bishiklik petroglyphs.

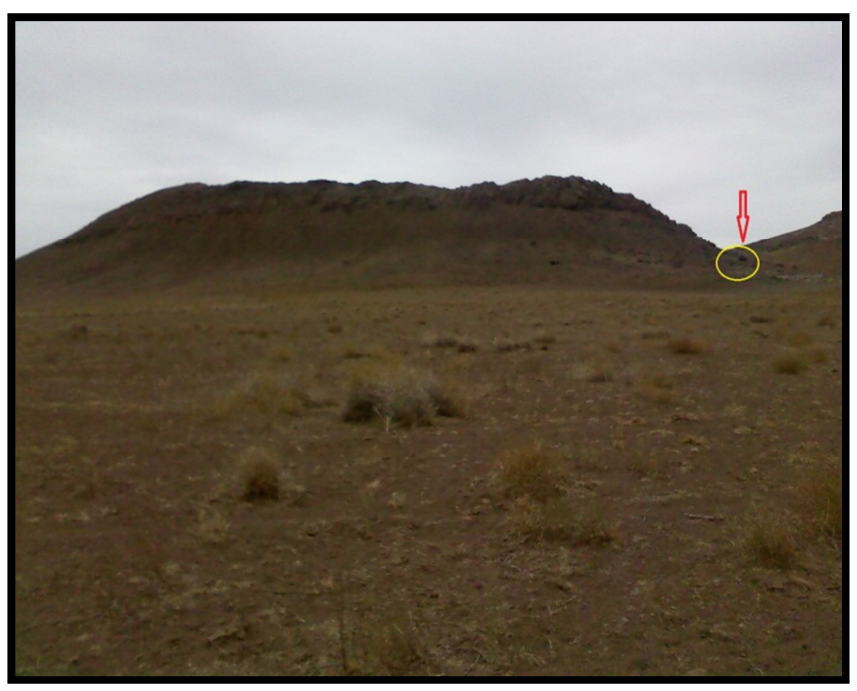

Figure 3. Bishiklik petroglyphs, view of the West.

\subsection{Diversity, Theme of Rocks and Quality of the Motifs}

On the smooth surface of the large boulder (12 motifs) and two smaller boulders ( 2 motifs), motifs in the single form and in a set have been engraved using threshing and carving techniques, which are probably related to the prehistoric era. All the motifs have been carved by negative Carving method by percussion igneous rocks, tibia bone of animals and metal. The depth and color of the motifs, their erosion pattern and retention are the factors that can be considered to determine the dating and history of their creation. Depth and color of the designs even those in the same scene are different. The depth of some motifs has been so eroded over time through the influence of natural factors that it is almost level with surface of the rock. Other motifs have been covered with patina and are of the same color with the rock, and so motifs with long backward horns higher than the real size are not clearly visible. Petroglyphs motifs include stylized animal motifs, mainly the mountain goat. Approximately 80percent of the motifs in Bishiklik are related to this animal. Mountain goat motif is the major motif petroglyphs of Iran. Nearly 80 percent of the rock engravings of Iran show the mountain goat motif with long symbolic horns implying the message of "water, rain, abundance, guarding the moon, guardian and savior of policy. This shared verbal and oral message on the pottery has remained from the Neolithic and especially chalcolithic period.

\subsection{Detailed Description of Motifs}

In general, the motifs include the designs of different animal motifs (mostly goats) and an image of man on horseback (Table 1). As noted above, mountain goat is the most frequent motif among the animal motifs. We hereby describe the motifs in detail. The motifs are coded based on English letters, and have been specified in Figure 4.

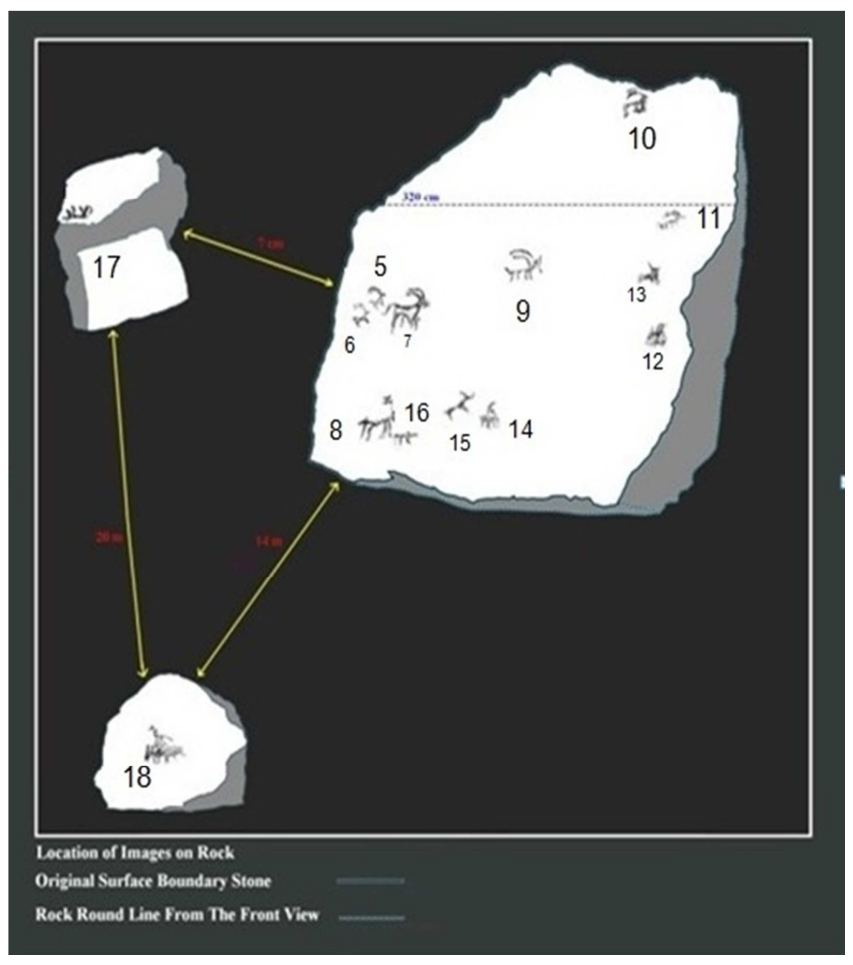

Figure 4. Location of images on Rocks and Relative to each other. 
Table 1. Described motifs Bishiklik petroglyphs in details.

\begin{tabular}{lllll}
\hline Number & $\begin{array}{l}\text { Images } \\
\text { Length }\end{array}$ & $\begin{array}{l}\text { Images } \\
\text { Heigth }\end{array}$ & $\begin{array}{l}\text { Horn } \\
\text { Length }\end{array}$ & The technique \\
\hline 5 & $15 \mathrm{~cm}$ & $18 \mathrm{~cm}$ & $12 \mathrm{~cm}$ & Carving \\
6 & $15 \mathrm{~cm}$ & $18 \mathrm{~cm}$ & $12 \mathrm{~cm}$ & Carving \\
7 & $37 \mathrm{~cm}$ & $36 \mathrm{~cm}$ & $17 \mathrm{~cm}$ & Carving \\
8 & $33 \mathrm{~cm}$ & $32 \mathrm{~cm}$ & $16 \mathrm{~cm}$ & Carving \\
9 & $32 \mathrm{~cm}$ & $14 \mathrm{~cm}$ & $10 \mathrm{~cm}$ & Carving \\
10 & $26 \mathrm{~cm}$ & $20 \mathrm{~cm}$ & $6 \mathrm{~cm}$ & Carving \\
11 & $16 \mathrm{~cm}$ & $11 \mathrm{~cm}$ & $10 \mathrm{~cm}$ & Carving \\
12 & $13 \mathrm{~cm}$ & $10 \mathrm{~cm}$ & - & percussion \\
13 & $26 \mathrm{~cm}$ & $18 \mathrm{~cm}$ & - & percussion \\
14 & $8 \mathrm{~cm}$ & $12 \mathrm{~cm}$ & - & percussion \\
15 & $22 \mathrm{~cm}$ & $17 \mathrm{~cm}$ & - & percussion \\
16 & $17 \mathrm{~cm}$ & $13 \mathrm{~cm}$ & - & percussion \\
17 & $18 \mathrm{~cm}$ & $8 \mathrm{~cm}$ & - & Carving \\
18 & $16 \mathrm{~cm}$ & $16 \mathrm{~cm}$ & - & percussion \\
\hline
\end{tabular}

- Goat motif: Goat motifs show a variety of designs in terms of morphology. Mountain goat is seen in a very high percentage compared to other animal motifs (all in the form of carving and threshing). The images are in profile and the motifs are overall stylized, body details are not displayed, and the goats have long exaggerated horns disproportionate with the body (Figure 5).

- Wild animal motif (?): There is a stylized motif of an animal from the canine family (probably Wolf) among the motifs(Figure 6). As these motifs have been created using threshing technique and because of the damage to them, it is difficult to distinguish the animal (Figures 7).

- Human motifs: The only motif in this category shows the profile of a person on horseback riding in a stylized fashion, and body details of the rider on horseback has not been indicated. This motif has been carved by threshing, and has been largely destroyed due to the natural factors (Figure 8).

- Horse motif: As noted above, only one horse motif is visible among the animal motifs, which shows a person on horseback and moving (Figure 8).

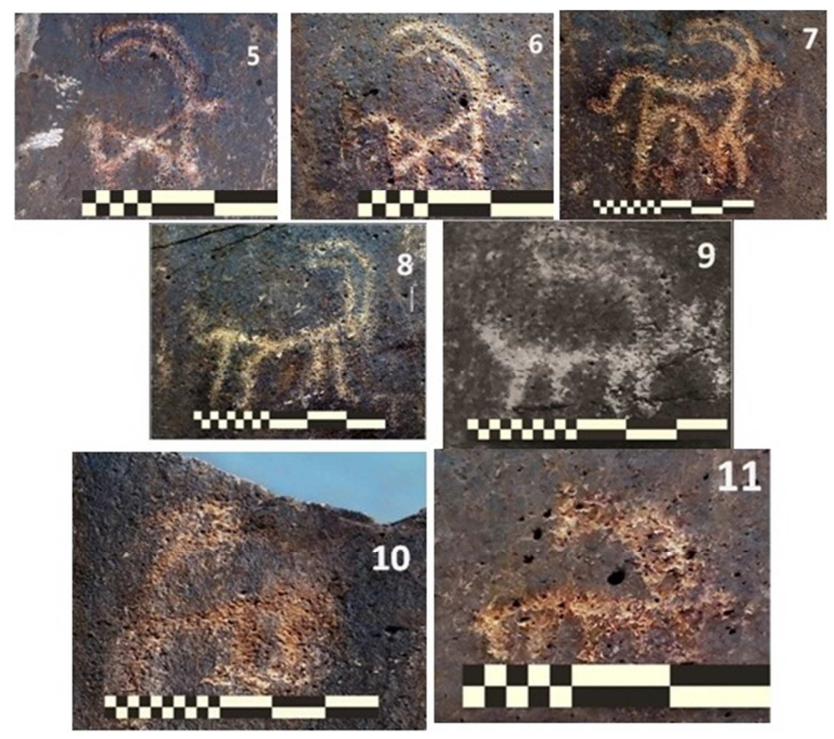

Figure 5. Bishiklik Goat Motif.

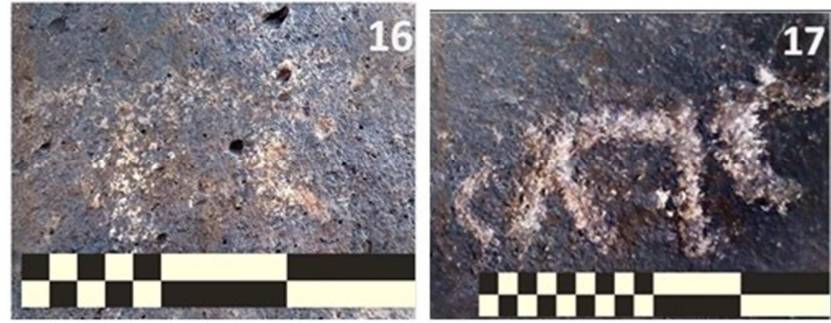

Figure 6. Bishiklik Canine Motif.
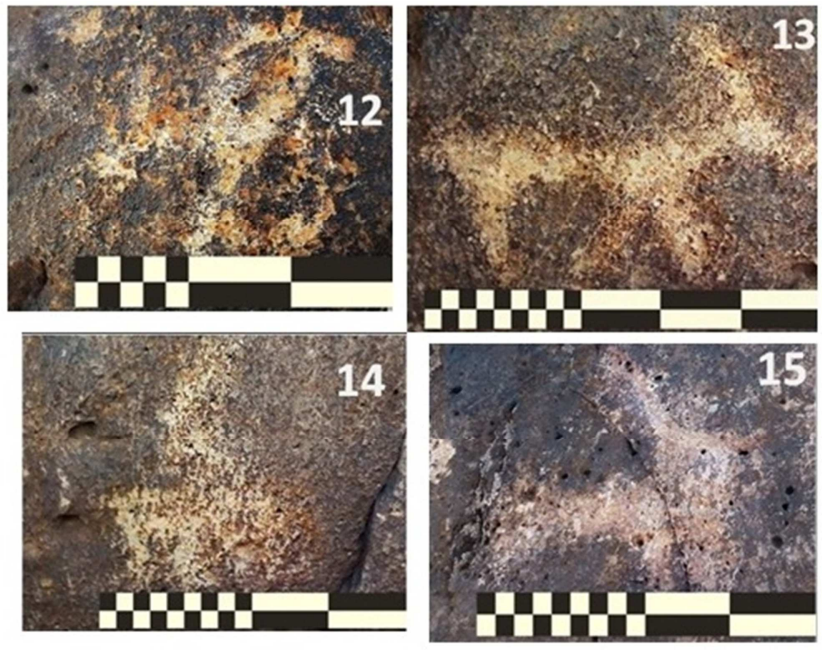

Figure 7. Bishiklik Unknown Motif?

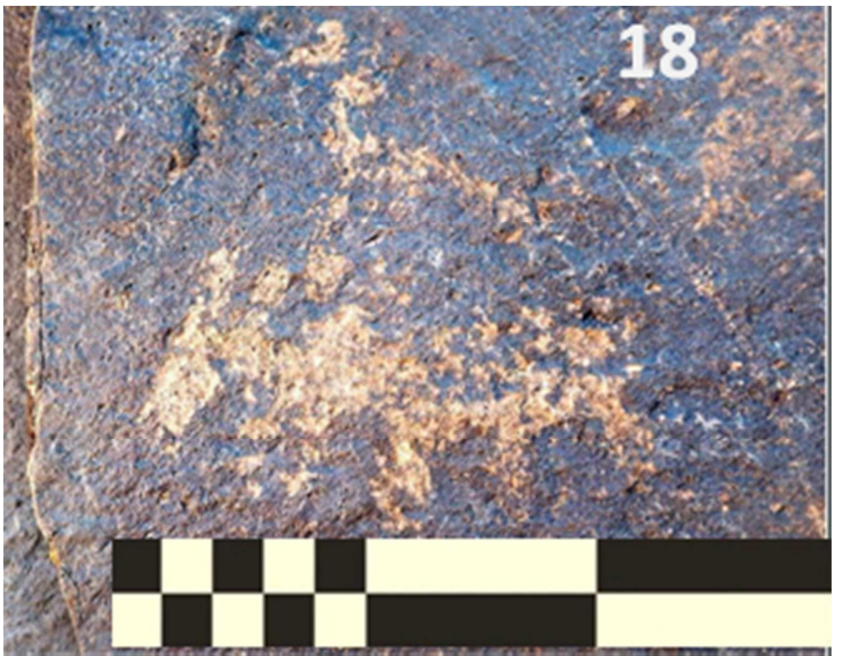

Figure 8. Bishiklik Horse Motif.

\section{Discussion}

Chronology as one of the most important issues of the rock engravings not only regarding the newly found motifs but in other parts of the country has remained elusive and unanswered. As mentioned by Rafifar concerning the rock art, in general the petroglyphs in most cases have no direct relationship with the land and its ancient layers (except for those observed in the caves, when it is clear that the ancient layers in the cave were contemporary with the engraved motifs). Therefore, the Rock engravings in an open space on 
natural boulders cannot be easily dated (Rafifar, 2002: 70). Archaeological survey and the landscape where these motifs are located is a basic approach in relation to the chronology of the petroglyphs. In this regard, the settlement radius of the areas subject to archaeological studies as well as similar works surrounding the stone engravings can be useful. Considering the nature of the rock on which the motifs have been carved, the depth of the engraved motif on rock surface, the geographical and climatic factors, the location of the motifs (the rocky shelters, caves or open area), adequate knowledge of the type and texture of the sediments that cover the rock surface and motifs over time, and the way these sediment layers have been formed on the surface of the stone and motifs and that sort of things can be useful in chronological studies (Mohammadi Qasryan, 2006: 63-64). Another current method in chronology is typology and evaluation of the images. Observation of specific datable signs in the motifs (line, motif of tools and harnesses, animals like horse, etc.) and their attribution to specific periods of time and knowing the date they were used are among the methods of determining the chronology ofpetroglyphs.

Motifs similar to those in Bishiklik can be seen in the mountains surrounding Torqabeh, Shandiz and Toos Plain in Khorasan Razavi Province (Bakhtyari shahri, 2009), Jarbat and Nargaslu in North Khorasan (Vahdati 2010) and Lakh Mazar in Birjand (Labaf Khaniki, 1997), Sarbisheh Byzham, Makhunak and Nehbandan in South Khorasan. In other parts of Iran, the rock engravings bearing similar motifs with our samples are relatively abundant. The mountain goat image is visible on rocks in many regions in Iran, including the samples identified in Kurdistan (southeast of city of Mahabad, Shahin Shahr, etc.) (Pedram 1994:79), Rock engravings of Arnan in Yazd (Shahrzadi, 1997: 142) and rock art in LeQan in East Azerbayejan (Rafifar,2004: 111).

\section{Conclusion}

It should be noted that no indication has been found so far for recent creation of these works. Local anthropological studies indicate that the local people or their ancestors have not been implicated in creation of such motifs. In terms of motif studies, a number of styles related to different periods can be distinguished for petroglyphs in question. Some motifs are completely organic and nature-oriented, and can be assumed the Earliest motifs of this collection in terms of typology and the extent of sediment cover. A remarkable feature of the set of rock motifs in Bishiklik is that they mostly represent mountain goat with long arcuate horns. The image of this animal can be observed from the early Neolithic period in different formats (pottery designs, effigies, etc.) in ancient Persia. Motifs of this animal are visible on rocks in different areas and cave walls, on pottery containers of Sialk, Susa, Ismael Abad, Tale Bakun, etc. In this case, according to the rock motifs of Bishiklik, which often show mountain goat and are similar to the pottery designs in the chalcolithic period.

\section{Acknowledgments}

We take this opportunity to appreciate the staunch collaboration of Mr. and Mrs. Soleymani who helped us prepare the report and images of Rock engravings, Ms. Nasim ferdosi, BSc student of archaeology of the University of Neyshabur who took the trouble to prepare the top and $\mathrm{Mr}$. Mehdi Khakzad, BSc student of mathematics in University of Neyshabur who prepared the portraits.

\section{References}

[1] Basafa, H., 2011. Cultures of the late Bronze and early Iron in Neyshabur Plain based on archaeological excavations of Firoozeh Township. Archaeology PhD thesis, Tarbiat Modarres University.

[2] Bakhtyari shahri, M. 1388. Evaluation of the newly found rock art of Toos Plain. Journal of Archaeological Studies, No. 1, pp. $21-44$.

[3] Bourny, Mc, 1969. Preliminary report of survey and excavation of caves in Kuhdasht, translated by Zabih Allah Rahmatian, archaeology and art of Iran, No. 3, pp. 14-16.

[4] Pedram, M. 1994. "Civilization of Mahabad", a collection of monuments from Qaleh dom to Takhte Soleyman, Tehran, Hur publishing.

[5] Rezaei, M. and Judy, Kh. 2010. Halush cave paintings; introduction, description, interpretation and chronology: web site of Journal of promotion and cultural anthropology: www.Anthropology.ir

[6] Rafifar, J. Rock engravings of Arasbaran (Songun): Journal of Anthropology, Volume I, Number I, Spring and Summer 2002, pp. 76-45.

[7] Rafifar, J. 2004. Rock in the North West of Iran (Hurand rock engravings), International Conference on Iranian Archaeology, North-West constituency. Pp. 111.

[8] Rafifar, J. 2005. Rock engravings of Arasbaran: Tehran, Iran Cultural Heritage and Tourism Organization.

[9] Riyazi, MR, 1992. Archaeological perspective of Neyshabur, Magazine of History and Archaeology, Year VI, No. 1, 2:20-31.

[10] Shahrzadi, D. 1997. Mountain rock art of Arnan in Yazd, archaeological reports. Pp. 133-142.

[11] Taheri, A., 2005. Introduction to the geography and history of Neyshabur, Neyshabur: mega city.

[12] Farhadi, M., 1998. Museums in wind, an essay on the anthropology of art (report of symbols and new found rock symbols of Timereh), Tehran, Allameh Tabatabai University.

[13] Garazhyan, O. 2008. Process of transition from the Chalcolithic to the Bronze Age in the North East of Iran, Tehran University $\mathrm{Ph} . \mathrm{D}$. dissertation in archaeology.

[14] Labaf Khaniki, M., 1997. Introducing Lakh Mazar rock engravings of Birjand, Iran Obituary First Gathering in Archaeology, Susa, 14-17 April 1994, Volume 1. Tehran: Cultural Heritage Organization, pp. 338-319. 
[15] Labaf Khaniki, M., 2009. Geochronology, archaeological research and interdisciplinary Studies, University Jihad, Tehran University, 113-126.

[16] Mohammadi Qasrian, S, 2007 a. Studies of rock engravings in Iran: Problems and Solutions: Ancient research, new volume, second year, No. 3, pp. 15-18.

[17] Watt, Kent, 2007. Foundations of environment. Translated by Vahabzadeh GH, Astan Quds Razavi press, Ninth Edition.
[18] Vahdati, AA, 2010. Canvas stone: evaluation report of two sets of rock art in Northern Khorasan Province (Jorbat and Upper Nargasluyi). Cultural Heritage and Tourism Organization of North Khorasan province.

[19] Velayati, A, 1988. Groundwater Resources and issues in Neyshabur Plain, Geographical Research Quarterly, 8: 96-123.

[20] Dessau, G, 1960. Rock engravings (Graffiti) from Iranian Baluchistan, East and West, Vol. 11, No. 1: 258-266. 